\title{
Pulmonary arterial hypertension associated with congenital heart disease: classification and pathophysiology
}

\author{
Robin Condliffe
}

\begin{abstract}
While the development of pulmonary arterial hypertension is not uncommon in adult congenital heart disease patients, other forms of pulmonary hypertension $(\mathrm{PH})$ may also be present. A good understanding of $\mathrm{PH}$ classification is therefore vital for clinicians managing adult patients with congenital heart disease. This paper reviews both the general classification of $\mathrm{PH}$ and more detailed approaches to classifying pulmonary arterial hypertension in association with congenital heart disease.
\end{abstract}

Keywords: Pulmonary hypertension, Pulmonary arterial hypertension, Congenital heart disease, Classification, Eisenmenger syndrome

\section{Background}

Pulmonary arterial hypertension (PAH) is not uncommon within the adult congenital heart disease (CHD) population, with estimates of prevalence ranging between $4.2-28 \%$ [1, 2]. Furthermore, other forms of Pulmonary Hypertension (PH) may also develop in CHD patients. Health care professionals who manage adult CHD patients, therefore, require in-depth understanding of the classification of $\mathrm{PH}$ in general and of the more detailed classification of $\mathrm{PAH}$ associated with CHD.

\section{Pulmonary hypertension classification}

Pulmonary hypertension has, until recently, been defined as the presence of a resting mean pulmonary arterial pressure (mPAP) of $\geq 25 \mathrm{mmHg}$ at right heart catheterisation $[3,4]$. More recently, the 6th World Symposium of PH (WSPH) has proposed two classification groups using lower mPAP thresholds: pre-capillary $\mathrm{PH}$, as defined by $\mathrm{mPAP}>20 \mathrm{mmHg}$, pulmonary

Correspondence: robin.condliffe@sth.nhs.uk

Pulmonary Vascular Disease Unit, Royal Hallamshire Hospital, S10 2JF, Sheffield, UK vascular resistance (PVR) $\geq 3$ Woods Units and left atrial pressure $\leq 15 \mathrm{mmHg}$ (measured by the pulmonary arterial wedge pressure, left ventricular end diastolic pressure or directly), and post-capillary $\mathrm{PH}$, defined by $\mathrm{mPAP}>20 \mathrm{mmHg}$ and left atrial pressure $>15 \mathrm{mmHg}$ [5]. Previous guidelines also defined $\mathrm{PH}$ by a mPAP > $30 \mathrm{mmHg}$ on exercise [6]. Although an abnormal increase in mPAP on exercise can be defined as mPAP/ cardiac output $>3$, it is not possible to reliably differentiate between pulmonary vascular disease and elevated left atrial pressure as the cause for this "abnormal" increase in pressure on exercise [7]. $\mathrm{PH}$ on exercise is not, therefore, part of current diagnostic criteria [5].

In addition to a haemodynamic approach, patients with $\mathrm{PH}$ can also be classified using a clinical approach which describes five groups with shared clinical and pathophysiological features (Table 1) [3]:

Group 1 (PAH) is characterised by a proliferative vasculopathy of the small pulmonary arteries resulting in increased pulmonary vascular resistance (PVR). PAH may be idiopathic (IPAH), may develop in patients exposed to various drugs and toxins (including amphetamines, amphetamine-related appetite suppressants, 
Table 1 Pulmonary hypertension classification [3]. Forms of pulmonary hypertension directly due to congenital cardiac and/ or pulmonary arterial defects in bold

1. Pulmonary Arterial Hypertension
1.1 Idiopathic
1.2 Heritable
1.2.1 BMPR2 mutation
1.2.2 Other mutations
1.3 Drugs and toxins induced
1.4 Associated with:
1.4.1 Connective tissue disease
1.4.3 Portal hypertension
1.4.4 Congenital heart disease
1.4.5 Schistosomiasis
1'. Pulmonary veno-occlusive disease/capillary haemangiomatosis
1'.1 Idiopathic
1'.2 Heritable
1'.2.1 ElF2AK4 mutation
1'.2.2 Other mutations
1'.3 Drugs, toxins and radiation induced
1'.4 Associated with:
1'.4.1 Connective tissue disease
1'.4.2 HIV infection
1". Persistent pulmonary hypertension of the newborn
2. Pulmonary hypertension due to left heart disease
2.1 Left ventricular systolic dysfunction
2.2 Left ventricular diastolic dysfunction
2.3 Valvular disease

2.4 Congenital/acquired left heart inflow/outflow tract obstruction and congenital cardiomyopathies

2.5 Congenital/acquired pulmonary veins stenosis

3. Pulmonary hypertension due to lung disease and/or hypoxia

3.1 Chronic obstructive pulmonary disease

3.2 Interstitial lung disease

3.3 Other pulmonary diseases with mixed restrictive and obstructive pattern

3.4 Sleep-disordered breathing

3.5 Alveolar hypoventilation disorders

3.6 Chronic exposure to high altitude

3.7 Developmental lung diseases

4. Chronic thromboembolic disease and other pulmonary arterial obstructions

4.1 Chronic thromboembolic pulmonary hypertension

4.2 Other pulmonary artery obstructions:

4.2.1 Angiosarcoma

4.2.2 Other intravascular tumours

4.2.3 Arteritis

4.2.4 Congenital pulmonary arterial stenoses
Table 1 Pulmonary hypertension classification [3]. Forms of pulmonary hypertension directly due to congenital cardiac and/ or pulmonary arterial defects in bold (Continued)

4.2.5 Parasites (hydatidosis)

5. Pulmonary hypertension with unclear and/or multifactorial mechanisms

5.1 Haematological disorders: chronic haemolytic anaemia, myeloproliferative disorders, splenectomy

5.2 Systemic disorders: sarcoidosis, pulmonary histiocytosis, lymphangioleiomyomatosis neurofibromatosis

5.3 Metabolic disorders: glycogen storage disease, Gaucher disease, thyroid disorders

5.4 Others: pulmonary tumoural thrombotic microangiopathy, fibrosing mediastinitis, chronic renal failure (with/without dialysis), segmental pulmonary hypertension

beta-interferon and some tyrosine kinase inhibitors) [8] or may be associated with other conditions, including $\mathrm{CHD}$, connective tissue disease, portal hypertension and human immunodeficiency virus (HIV). Estimates of the prevalence of $\mathrm{PAH}$ within adult $\mathrm{CHD}$ patients range between $4.2-28 \%[1,2]$. Approximately $20 \%$ of patients with IPAH have a mutation in bone morphogenetic protein receptor-2 (BMPR-2), while $70 \%$ of patients with a family history of $\mathrm{PAH}$ also have this mutation; those patients with a BMPR-2 mutation and/or clear family history of $\mathrm{PAH}$ are described as having heritable PAH [9].

Group 2 (PH due to left heart disease, PH-LHD) may develop as a result of left ventricular systolic or diastolic dysfunction or valvular disease. In PH-LHD, raised pulmonary arterial pressure may develop purely due to passive "back-pressure" from the left heart (isolated post-capillary $\mathrm{PH}$ ) or a secondary pulmonary arterial vasculopathy may be present (combined pre and post-capillary $\mathrm{PH}$, typified by elevated left atrial pressure but a high PVR and/or diastolic pulmonary pressure minus mean wedge pressure, the diastolic pressure gradient) [10].

Group 3 (PH due to lung disease, PH-Lung) may be present in association with airways disease (e.g. chronic obstructive disease including emphysema), parenchymal disease (e.g. pulmonary fibrosis) and hypoventilation (e.g. neuromuscular disease and obesity hypoventilation) $[11,12]$.

Group 4 disease (chronic thromboembolic PH, CTEP H) occurs when there is impaired fibrinolysis of thromboembolic disease resulting in stenoses within the pulmonary arterial lumen [13].

Group 5 comprises conditions with uncertain or multiple possible aetiologies for the development of PH (including sarcoidosis, haemolytic anaemias and Langerhans Cell Histiocytosis). 


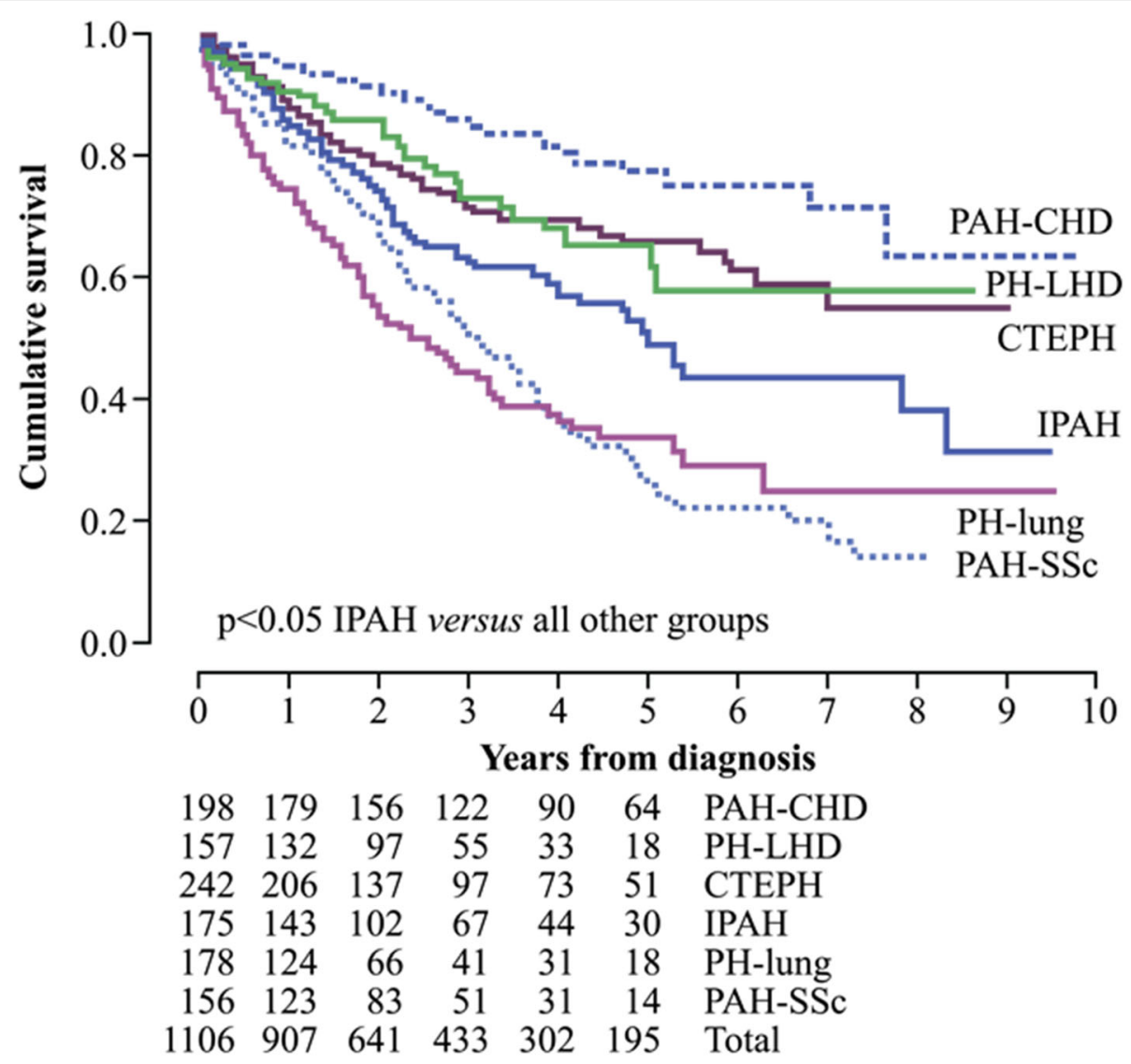

Fig. 1 Survival of patients with PH is significantly related to the form of PH [14]. Abbreviations: PAH-CHD, pulmonary arterial hypertension associated with congenital heart disease; PH-LHD, pulmonary hypertension associated with left heart disease; CTEPH, chronic thromboembolic pulmonary hypertension; IPAH, idiopathic pulmonary arterial hypertension; PH-lung, pulmonary hypertension associated with lung disease; PAHSSc, pulmonary arterial hypertension associated with systemic sclerosis. Reproduced with permission of the@ ERS 2019: European Respiratory Journal 39 (4) 945-955; DOI: https://doi.org/10.1183/09031936.00078411 Published 31 March 2012

The precise form of $\mathrm{PH}$ impacts significantly not only on the optimal treatment (which may include PAHspecific therapies, intervention for CTEPH in the form of pulmonary endarterectomy or balloon pulmonary angioplasty or optimisation of treatment of underlying cardiorespiratory disease), but also on prognosis (Fig. 1) [14].

\section{Pulmonary arterial hypertension associated with congenital heart disease}

Patients with PAH associated with CHD (PAH-CHD) may be further classified in 2 main ways:

\section{Clinical classification}

First, a clinical classification comprising 4 groups can be described (Table 2) [3]. This classification system provides a clinically useful method of grouping patients with similar therapies and outcomes:
Table 2 Clinical classification of PAH-CHD [15]

\section{A. Eisenmenger Syndrome \\ Large congenital systemic-to-pulmonary shunt leading to pulmonary vasculopathy, increased PVR and reversal of shunt. Cyanosis and erythro- cytosis present.}

\section{B. PAH associated with a predominant systemic-to-pulmonary shunt}

Moderate-large shunt with mild-moderately increased pulmonary vascular resistance. Patient is not cyanotic at rest. Defect may be correctable or non-correctable.

\section{PAH associated with a small defect}

Significantly elevated pulmonary vascular resistance in the presence of a small defect (ASD $<2 \mathrm{~cm}$ diameter, VSD $<1 \mathrm{~cm}$ diameter). Often behaves similarly to idiopathic pulmonary arterial hypertension.

\section{PAH associated with a repaired defect}

PAH persists after closure or develops/recurs following closure. 
a. Group A (Eisenmenger Syndrome [ES]) is characterised by increased flow and pressure due to a large unrepaired systemic-to-pulmonary shunt resulting in the development of a pulmonary vasculopathy. Heath and Edwards described six histological grades of pulmonary vascular disease in ES, with progressive changes within the intima and media leading to narrowing of the pulmonary arterial bed (Fig. 2) [16]. This process results in increased PVR and subsequent shunt reversal, leading to cyanosis and subsequent secondary erythrocytosis. Subsequent studies have identified the importance of inflammation in the development of this vasculopathy, together with abnormal levels of endothelin, nitric oxide and prostacyclin [17].

b. Group B includes patients with moderate-to-large left-to-right shunts and is characterised by mild-tomoderately increased PVR in the absence of cyanosis. These shunts may be amenable to closure depending on both the PVR and the nature of the shunt.

c. Group C disease is characterised by small defects (atrial septal defect [ASD] $<2 \mathrm{~cm}$ diameter or ventricular septal defect [VSD] $<1 \mathrm{~cm}$ diameter, so-called bystander lesions), which are felt unlikely to be responsible for the development of PAH. In the context of significant established $\mathrm{PAH}$, the defect acts to reduce right ventricular afterload by acting as a "relief valve" and should not be closed. d. Group D consists of patients with the development or recurrence of $\mathrm{PAH}$ following the repair of a defect.

\section{Anatomical-pathophysiological}

The second form of classification of PAH-CHD is the anatomical-pathophysiological system (Table 3) [18]. This system uses 5 criteria to describe a lesion: type, size, shunt direction, associated abnormalities and repair status.

The anatomical-pathophysiological system may be used to complement and further refine the clinical classification system. Although as a whole, group A (ES) is associated with superior outcomes when compared with group D [19], patients with different underlying defects and ES are likely to have different outcomes. For example, patients with post-tricuspid defects have superior survival from diagnosis when compared with those with pre-tricuspid defects (Fig. 3) [20]. This presumably reflects better adaptation of the right ventricle, which has been pressure-loaded from an early age, with a persistent foetal phenotype [21]. The appreciation of poorer survival in those with pre-tricuspid defects may, therefore, stimulate earlier and more aggressive PAH treatment. The reason why a minority of patients with a large unrepaired atrial septal defect with initial volume-loading of the right heart develop ES is unclear; some groups have proposed a "second-hit" hypothesis, whereby an underlying genetic abnormality predisposes to the development of PAH [22].

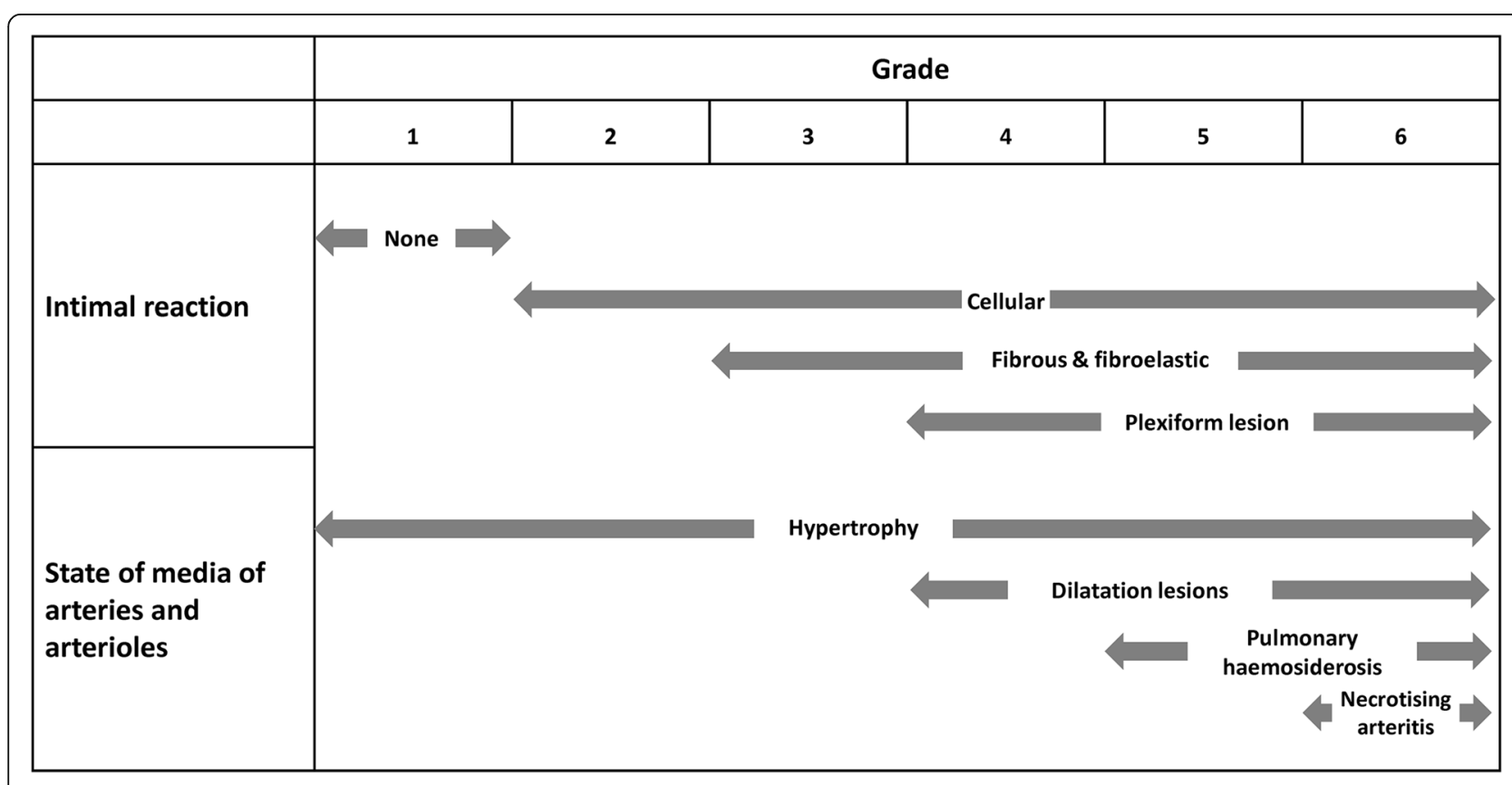

Fig. 2 Heath-Edwards classification [16] 
Table 3 Anatomical-pathophysiological classification [18]

1. Type
1.1.1. Atrial septal defect (ASD)
1.1.1.1 Ostium secundum
1.1.1.2 Sinus venosus
1.1.1.3 Ostium primum
1.1.2 Total or partial unobstructed anomalous pulmonary venous
return
1.2 Simple post-tricuspid shunts
1.2.1 Ventricular septal defect (VSD)
1.2.2 Patent ductus arteriosus
1.3 Combined shunts
Describe combination and define predominant defect
1.4 Complex congenital heart disease
1.4.1 Complete atrioventricular septal defect
1.4.2 Truncus arteriosus
1.4.3 Single ventricle physiology with unobstructed pulmonary
blood flow
1.4.4 Transposition of the great arteries with VSD (without
pulmonary stenosis) and/or patent ductus arteriosus
1.4.5 Other

2. Dimension (specify for each defect if more than one congenital heart defect exists)

2.1 Haemodynamic (specify ratio of pulmonary and systemic blood flow, Qp:Qs)

2.1.1 Restrictive (pressure gradient across the defect)

2.1.2 Non-restrictive

2.2 Anatomic

2.2.1 Small to moderate (ASD $\leq 2.0 \mathrm{~cm}$ and VSD $\leq 1.0 \mathrm{~cm}$ )

2.2.2 Large (ASD $>2.0 \mathrm{~cm}$ and VSD $>1.0 \mathrm{~cm}$ )

3. Direction of shunt

3.1 Predominantly systemic-to-pulmonary

3.2 Predominantly pulmonary-to-systemic

3.3 Bidirectional

4. Associated cardiac and extracardiac abnormalities

5. Repair status

5.1 Unoperated

5.2 Palliated [specify type of operation(s), age at surgery]

5.3 Repaired [specify type of operation(s), age at surgery]

\section{Other forms of PH in association with CHD}

As well as PAH, other forms of PH may develop in association with CHD (Table 1):

\section{Group 2}

$\mathrm{PH}$ in association with increased left heart filling pressures may develop for a variety of reasons due to CHD, including congenital left heart valvular disease, congenital left ventricular outflow tract obstruction and congenital pulmonary vein stenosis. PH-LHD may also develop in patients with CHD due to comorbid acquired heart disease, including acquired valvular disease and systolic or diastolic dysfunction unrelated to the CHD.

\section{Group 3}

Restrictive or obstructive pulmonary function is not uncommon in patients with CHD [23, 24]. Patients with congenital abnormalities may also develop acquired respiratory disease, for example the incidence of obstructive sleep apnoea in patients with Down syndrome is estimated to be $>50 \%[25]$.

\section{Group 4}

In situ thrombus may develop in $21 \%$ of patients with ES [26]. Although it is often mural and non-obstructive, pulmonary arterial obstruction may occur, which can further contribute to increased pulmonary vascular resistance. Congenital (peripheral) pulmonary arterial stenoses may also result in a rise in pulmonary artery pressures and right ventricular overload.

\section{Group 5}

Segmental PH is included in group $5 \mathrm{PH}$ and is characterised by abnormal cardiovascular anatomy resulting in distal pulmonary vascular disease differentially affecting pulmonary segments. A typical example is tetralogy of Fallot with pulmonary atresia and aorto-pulmonary collaterals which often results in pulmonary vascular disease in some, but not all, segments of the lung [27].

\section{Fontan circulation}

Fontan procedures performed in patients with univentricular physiology result in a single circulation in which the pulmonary and systemic circulations run in series [28]. The ventricle is therefore committed to the systemic circulation while caval return is redirected to the pulmonary arteries without the support of a subpulmonary ventricle. This system requires low PVR to maintain preload of the single ventricle and systemic venous hypertension to drive blood through the pulmonary circulation. Pulmonary vascular remodelling is known to occur in patients with a Fontan circulation $[29,30]$. Therefore, although patients with a Fontan circulation cannot develop $\mathrm{PH}$ as conventionally defined (mPAP $\geq 25 \mathrm{mmHg}$ ), an increase in PVR may develop with adverse effects on functioning of the circulation [28]. Pulmonary vasodilator therapies may therefore sometimes be used even though definitive evidence regarding efficacy, timing and type of therapy to use in this cohort remains controversial [31-33]. 


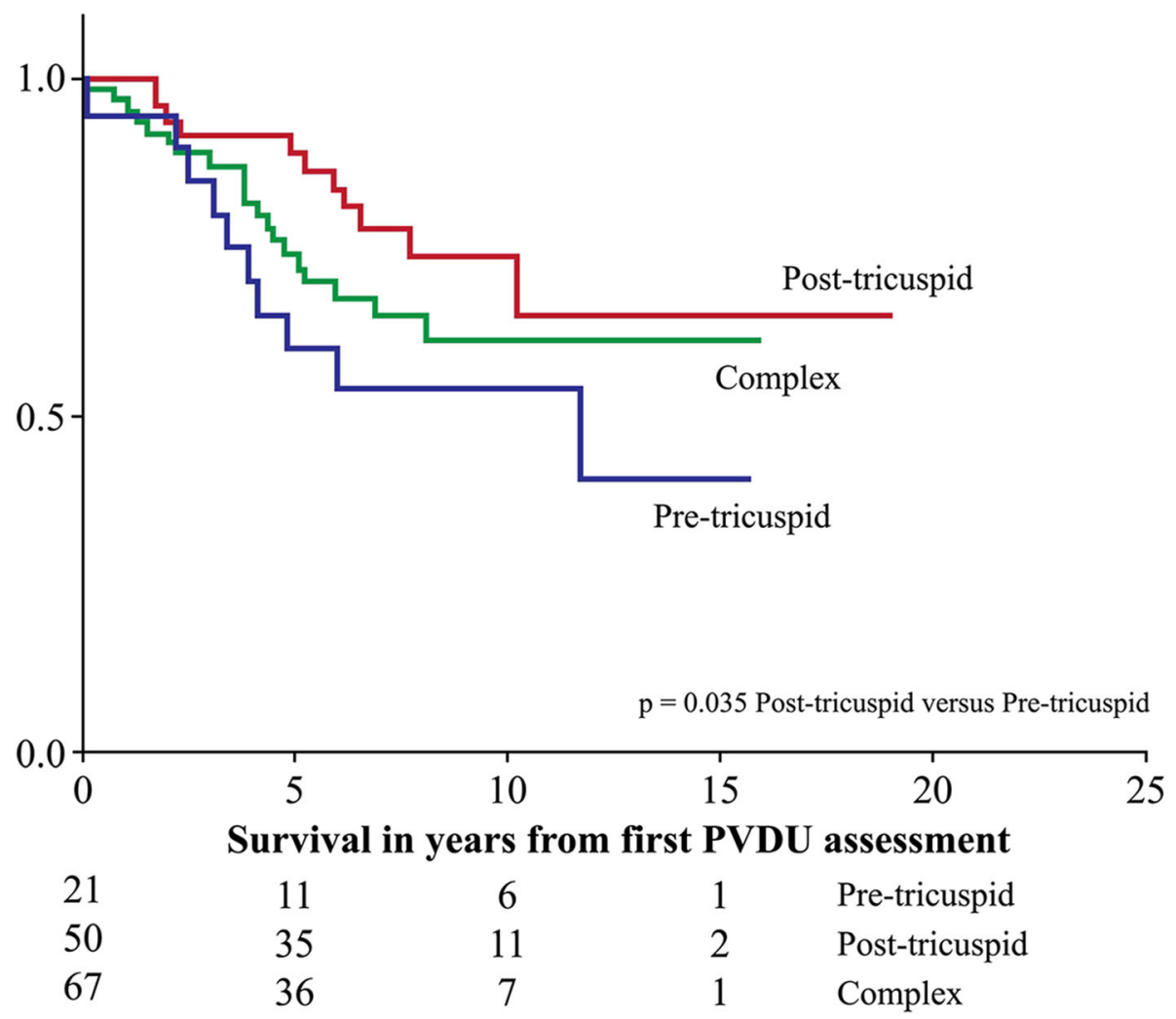

Fig. 3 Survival in Eisenmenger Syndrome from time of referral to pulmonary vascular disease unit according to type of defect [19]

\section{Conclusion}

A good understanding of the general classification of $\mathrm{PH}$ and of the more detailed approaches to classifying PAH$\mathrm{CHD}$ is vital for clinicians managing adult patients with congenital heart disease.

\section{Abbreviations}

BMPR-2: Bone morphogenetic protein receptor-2; CHD: Congenital heart disease; CTEPH: Chronic thromboembolic PH; ES: Eisenmenger Syndrome; HIV: Human immunodeficiency virus; mPAP: Mean pulmonary arterial pressure; PAH: Pulmonary arterial hypertension; PH: Pulmonary hypertension; PH-LHD: PH due to left heart disease; PVDU: Pulmonary vascular disease unit; PVR: Pulmonary vascular resistance

\section{Acknowledgements}

Not applicable.

\section{About this supplement}

This article has been published as part of Journal of Congenital Cardiology Volume 4 Supplement 1 2020: Unmet needs in Pulmonary Hypertension associated with Adult Congenital Heart Disease (ACHD-PH). The full contents of the supplement are available at https://jcongenitalcardiology. biomedcentral.com/articles/supplements/volume-4-supplement-1.

\section{Author's contributions}

The author was fully responsible for the design and writing of this article. The author(s) read and approved the final manuscript.

\section{Funding}

Medical writing support was provided by nspm Itd, Meggen, Switzerland. The manuscript was funded by a Medical and Educational Goods and Services (MEGS) grant and Actelion Pharmaceuticals UK Limited (who had no influence on manuscript writing).

\section{Availability of data and materials \\ Not applicable.}

Ethics approval and consent to participate

Not applicable.

\section{Consent for publication}

Not applicable.

\section{Competing interests}

$\mathrm{RC}$ has received honoraria for lecturing and advisory boards from Actelion, Bayer, GSK and MSD.

Received: 12 November 2020 Accepted: 12 November 2020 Published: 16 December 2020

\section{References}

1. Duffels MG, Engelfriet PM, Berger RM, van Loon RL, Hoendermis E, Vriend $J W$, et al. Pulmonary arterial hypertension in congenital heart disease: an epidemiologic perspective from a Dutch registry. Int J Cardiol. 2007;120(2): 198-204.

2. Engelfriet PM, Duffels MG, Moller T, Boersma E, Tijssen JG, Thaulow E, et al. Pulmonary arterial hypertension in adults born with a heart septal defect: the euro heart survey on adult congenital heart disease. Heart. 2007:93(6):682-7.

3. Galie N, Humbert M, Vachiery JL, Gibbs S, Lang I, Torbicki A, et al. 2015 ESC/ ERS guidelines for the diagnosis and treatment of pulmonary hypertension: the joint task force for the diagnosis and treatment of pulmonary hypertension of the European Society of Cardiology (ESC) and the European Respiratory Society (ERS): endorsed by: Association for European Paediatric and Congenital Cardiology (AEPC), International Society for Heart and Lung Transplantation (ISHLT). Eur Heart J. 2016:37(1):67-119.

4. Hoeper MM, Bogaard HJ, Condliffe R, Frantz R, Khanna D, Kurzyna M, et al. Definitions and diagnosis of pulmonary hypertension. J Am Coll Cardiol. 2013;62(25 Suppl):D42-50. 
5. Simonneau G, Montani D, Celermajer DS, Denton CP, Gatzoulis MA, Krowka $M$, et al. Haemodynamic definitions and updated clinical classification of pulmonary hypertension. Eur Respir J. 2019;53:1.

6. Barst RJ, McGoon M, Torbicki A, Sitbon O, Krowka MJ, Olschewski H, et al. Diagnosis and differential assessment of pulmonary arterial hypertension. J Am Coll Cardiol. 2004;43(12 Suppl S):40S-7S

7. Kovacs G, Herve P, Barbera JA, Chaouat A, Chemla D, Condliffe R, et al. An official European Respiratory Society statement: pulmonary haemodynamics during exercise. Eur Respir J. 2017;50:5.

8. Montani D, Seferian A, Savale L, Simonneau G, Humbert M. Drug-induced pulmonary arterial hypertension: a recent outbreak. Eur Respir Rev. 2013;22(129):244-50.

9. Liu D, Morrell NW. Genetics and the molecular pathogenesis of pulmonary arterial hypertension. Curr Hypertens Rep. 2013;15(6):632-7.

10. Opitz CF, Hoeper MM, Gibbs JS, Kaemmerer H, Pepke-Zaba J, Coghlan JG, et al. Pre-capillary, combined, and post-capillary pulmonary hypertension: a pathophysiological continuum. J Am Coll Cardiol. 2016;68(4):368-78.

11. Hurdman J, Condliffe R, Elliot CA, Swift A, Rajaram S, Davies C, et al. Pulmonary hypertension in COPD: results from the ASPIRE registry. Eur Respir J. 2013:41(6):1292-301.

12. Corte TJ, Wort SJ, Wells AU. Pulmonary hypertension in idiopathic pulmonary fibrosis: a review. Sarcoidosis Vasc Diffuse Lung Dis. 2009;26(1):7-19.

13. Condliffe R, Kiely DG, Gibbs JS, Corris PA, Peacock AJ, Jenkins DP, et al. Improved outcomes in medically and surgically treated chronic thromboembolic pulmonary hypertension. Am J Respir Crit Care Med. 2008;177(10):1122-7.

14. Hurdman J, Condliffe R, Elliot CA, Davies C, Hill C, Wild JM, et al. ASPIRE registry: assessing the Spectrum of pulmonary hypertension identified at a REferral Centre. Eur Respir J. 2012;39(4):945-55.

15. Galie N, Humbert M, Vachiery JL, Gibbs S, Lang I, Torbicki A, et al. 2015 ESC/ ERS guidelines for the diagnosis and treatment of pulmonary hypertension. Rev Esp Cardiol (Engl Ed). 2016;69(2):177.

16. Heath D, Edwards JE. The pathology of hypertensive pulmonary vascular disease; a description of six grades of structural changes in the pulmonary arteries with special reference to congenital cardiac septal defects. Circulation. 1958;18(4 Part 1):533-47.

17. Humbert M, Morrell NW, Archer SL, Stenmark KR, MacLean MR, Lang IM, et al. Cellular and molecular pathobiology of pulmonary arterial hypertension. J Am Coll Cardiol. 2004;43(12 Suppl S):13S-24S.

18. Galie N, Hoeper MM, Humbert M, Torbicki A, Vachiery JL, Barbera JA, et al. Guidelines for the diagnosis and treatment of pulmonary hypertension: the task force for the diagnosis and treatment of pulmonary hypertension of the European Society of Cardiology (ESC) and the European Respiratory Society (ERS), endorsed by the International Society of Heart and Lung Transplantation (ISHLT). Eur Heart J. 2009;30(20):2493-537.

19. Manes A, Palazzini M, Leci E, Bacchi Reggiani ML, Branzi A, Galie N. Current era survival of patients with pulmonary arterial hypertension associated with congenital heart disease: a comparison between clinical subgroups. Eur Heart J. 2014;35(11):716-24.

20. Ramjug S, Hussain N, Hurdman J, Billings C, Charalampopoulos A, Elliot CA, et al. Pulmonary arterial hypertension associated with congenital heart disease: comparison of clinical and anatomic-pathophysiologic classification. J Heart Lung Transplant. 2016;35(5):610-8.

21. Moceri P, Kempny A, Liodakis E, Alonso Gonzales R, Germanakis I, Diller GP, et al. Physiological differences between various types of Eisenmenger syndrome and relation to outcome. Int J Cardiol. 2015;179:455-60.

22. Gatzoulis MA, Beghetti M, Landzberg MJ, Galie N. Pulmonary arterial hypertension associated with congenital heart disease: recent advances and future directions. Int J Cardiol. 2014;177(2):340-7.

23. Alonso-Gonzalez R, Borgia F, Diller GP, Inuzuka R, Kempny A, MartinezNaharro A, et al. Abnormal lung function in adults with congenital heart disease: prevalence, relation to cardiac anatomy, and association with survival. Circulation. 2013;127(8):882-90.

24. Broberg CS, Van Woerkom RC, Swallow E, Dimopoulos K, Diller GP, Allada G, et al. Lung function and gas exchange in Eisenmenger syndrome and their impact on exercise capacity and survival. Int J Cardiol. 2014;171(1):73-7.

25. Chamseddin BH, Johnson RF, Mitchell RB. Obstructive sleep apnea in children with Down syndrome: demographic, clinical, and Polysomnographic features. Otolaryngol Head Neck Surg. 2018; 194599818797308

26. Silversides CK, Granton JT, Konen E, Hart MA, Webb GD, Therrien J. Pulmonary thrombosis in adults with Eisenmenger syndrome. J Am Coll Cardiol. 2003;42(11):1982-7.
27. Dimopoulos K, Diller GP, Opotowsky AR, D'Alto M, Gu H, Giannakoulas G, et al. Definition and Management of Segmental Pulmonary Hypertension. J Am Heart Assoc. 2018;7:14

28. Clift $\mathrm{P}$, Celermajer D. Managing adult Fontan patients: where do we stand? Eur Respir Rev. 2016;25(142):438-50.

29. Levy M, Danel C, Tamisier D, Vouhe P, Leca F. Histomorphometric analysis of pulmonary vessels in single ventricle for better selection of patients for the Fontan operation. J Thorac Cardiovasc Surg. 2002;123(2):263-70.

30. Mitchell MB, Campbell DN, Ivy D, Boucek MM, Sondheimer HM, Pietra B, et al. Evidence of pulmonary vascular disease after heart transplantation for Fontan circulation failure. J Thorac Cardiovasc Surg. 2004;128(5):693-702.

31. Giardini A, Balducci A, Specchia S, Gargiulo G, Bonvicini M, Picchio FM. Effect of sildenafil on haemodynamic response to exercise and exercise capacity in Fontan patients. Eur Heart J. 2008;29(13):1681-7.

32. Hebert A, Mikkelsen UR, Thilen U, Idorn L, Jensen AS, Nagy E, et al. Bosentan improves exercise capacity in adolescents and adults after Fontan operation: the TEMPO (treatment with Endothelin receptor antagonist in Fontan patients, a randomized, placebo-controlled, double-blind study measuring peak oxygen consumption) study. Circulation. 2014;130(23):2021-30.

33. Rhodes J, Ubeda-Tikkanen A, Clair M, Fernandes SM, Graham DA, Milliren CE, et al. Effect of inhaled iloprost on the exercise function of Fontan patients: a demonstration of concept. Int J Cardiol. 2013;168(3):2435-40.

\section{Publisher's Note}

Springer Nature remains neutral with regard to jurisdictional claims in published maps and institutional affiliations.
Ready to submit your research? Choose BMC and benefit from:

- fast, convenient online submission

- thorough peer review by experienced researchers in your field

- rapid publication on acceptance

- support for research data, including large and complex data types

- gold Open Access which fosters wider collaboration and increased citations

- maximum visibility for your research: over $100 \mathrm{M}$ website views per year

At BMC, research is always in progress.

Learn more biomedcentral.com/submissions 